cold solution with 15 grams of crystallized ammonium bicarbonate dissolved in Ioc cc. of water and cooled to zero. The washing and filtering of the precipitate were carried out as described above. In each preparation the precipitate was washed with ice water saturated with carbon dioxide, then with alcohol and ether and finally it was dried on the cold filter paper in the ice trough. Five preparations were made and analyzed, showing the following percentage loss of weight on drying at $120^{\circ}:(1), 16.4$, 16.3 ; (2) $25.48,23.01$; (3) $47.18,39.87$; (4) $38.52,37.43$; (5) $40.86,39.75$.

Evidently the first and second preparations had undergone partial decomposition and the high results in the first determination of the third preparation must have been due to the presence of a small quantity of ether which had not evaporated. The remaining analyses indicate that the acid carbonate of barium like that of calcium has a higher proportion of carbonic acid than is ordinarily assigned to it. Our results show that the acid carbonate of barium, like that of calcium, can be prepared by double decomposition of an alkali bicarbonate and barium chloride, provided the temperature be kept near zero. The barium acid carbonate can be separated from the solution, washed and dried, but owing to slow decomposition it is difficult to determine its quantitative composition.

In preparing it, it is also necessary to have the solutions not too dilute. If the solutions are diluted with ice water to three or four times the volumes mentioned, and then mixed, they remain perfectly clear because of the solubility of acid barium carbonate. Now, on heating the clear solution, as the temperature goes up, the normal carbonate is precipitated in granular form.

The experiments described in this paper were made during the winter of $1903-04$.

WASHINGTON UNIVERSITY, ST, LOUIS, MO.

\title{
ON THE COMPOSITION OF THE ACID CARBONATES OF CALCIUM AND BARIUM.
}

BY EDWARD H. KEISER AND IEROY MCMASTER,

Received August 18 , Ig08.

The work of Keiser and Leavitt, in the preceding paper, has shown that it is possible to prepare the acid carbonates of calcium and barium by double decomposition and to separate them from the solution in which they have been formed. It is difficult, however, to get them in dry condition for analysis without having them undergo partial decomposition. Thinking that there may perhaps have been a trace of moisture or of ether in the compounds that were analyzed, we determined to modify the method of analysis and without attempting to dry and weigh them to 
determine, for example, the ratio of barium oxide to carbon dioxide in the acid carbonate of barium.

The method of preparation was similar to that described by Keiser and Leavitt, except that we formed the compound in a solution containing gelatin. The object of the gelatin was to retard the decomposition of the acid carbonate. In order to make a series of precipitations, we made up a solution of crystallized barium chloride containing 21 grams to the liter, one of ammonium bicarbonate, containing 31.6 grams to the liter, and a solution of gelatin, made by boiling pure gelatin with water and diluting it to such an extent that it did not gelatinize when it was cooled to zero. This gelatin solution was neutral to phenolphthalein, litmus and methyl orange. The barium chloride had been recrystallized and the ammonium bicarbonate gave on analysis, 55.2 per cent. carbon dioxide instead of the theoretical 55.5 per cent. Ioo $\mathrm{cc}$. of the barium chloride and of the bicarbonate solutions were measured into separate beakers and $25 \mathrm{cc}$. of gelatin solution added to each. A lump of ice was put into each and when the temperature had fallen to zero, the solutions were mixed. Precipitation did not take place immediately as when no gelatin is present, but in from five to seven minutes the acid carbonate came down. Washed carbon dioxide from a Kipp's apparatus was now passed into the beaker for about ten minutes. The liquid was now poured upon a filter and the precipitate washed five times with ice water charged with carbon dioxide. After washing, the filter with acid carbonate on it was placed in a flask and tightly stoppered with a rubber stopper, carrying a separating funnel in one hole, and in the other hole a delivery tube sealed at the end but with a hole in the side half an inch above the sealed end. This tube had been drawn up into the stopper so that when the stopper was forced into the flask no gas could escape. The flask was now packed in snow or ice until the determination of carbon dioxide was made. This much of the work was done out of doors in the morning of cold winter days, when the ground was covered with snow, and the temperature of the air was below freezing.

To determine the ratio of carbon dioxide to barium oxide in the precipitate, the flasks were removed to the laboratory and connected with the apparatus for the gravimetric determination of carbon dioxide. The delivery tube with sealed end was pushed down through the stopper until the hole opened into the flask and the gas could pass into the drying tubes and finally into the weighed potash bulb. Dilute hydrochloric acid was then admitted by means of the separating funnel and the acid carbonate completely decomposed and the carbon dioxide all swept in to the weighed potash bulbs.

The barium chloride solution remaining in the flask was then filtered, 
to remove the filter paper, and made up to definite volume and an aliquot part taken for the determination of barium. The latter was weighed as barium sulphate. Five preparations of acid barium carbonate were made in this way and the following results were obtained from the analyses:

\begin{tabular}{|c|c|c|}
\hline Weight of BaO. & Weight of $\mathrm{CO}_{2}$. & $\begin{array}{l}\text { Ratio of molecules } \\
\text { of } \mathrm{CO}_{2} \text { to } \mathrm{I} \text { of } \mathrm{BaO}\end{array}$ \\
\hline I $\ldots \ldots \ldots \ldots \ldots .4839$ & 0.3716 & 2.67 \\
\hline$\ldots \ldots \ldots 0.3156$ & 0.2342 & $2.5^{8}$ \\
\hline $3 \ldots \ldots \ldots \ldots \ldots 0.3062$ & 0.2286 & 2.60 \\
\hline $4 \ldots \ldots \ldots \ldots \ldots \ldots .3823$ & 0.2900 & 2.63 \\
\hline $5 \ldots \ldots \ldots \ldots \ldots \ldots .3647$ & 0.2522 & $2.4 \mathrm{I}$ \\
\hline & Avera & $2.5^{8}$ \\
\hline
\end{tabular}

The ratio of molecules was calculated in the following way: $(\mathrm{BaO})$ : $\left(\mathrm{CO}_{2}\right) \mathrm{X}$ : : wt. of $\mathrm{BaO}:$ wt. of $\mathrm{CO}_{2}$; substituting the figures $153:(44)$ $X:: 0.4839: 0.3716, X=2.67$. From our results it appears that the acid carbonate of barium contains more than two molecules of carbon dioxide for one of barium oxide. Our analyses would indicate some such formula as $\mathrm{BaCO}_{3}$. I.5 $\left(\mathrm{H}_{2} \mathrm{CO}_{3}\right)$.

We have also determined the ratio of molecules of carbon dioxide to one molecule of lime in solutions of the acid carbonate of calcium at the ordinary temperature. We proceeded as follows: Purified carbon dioxide was passed into clear lime water, containing a drop of phenolphthalein, until the pink color disappeared and the calcium carbonate first formed had largely dissolved. This solution was now filtered. It contained acid calcium carbonate and excess of carbon dioxide. To remove the latter it was now rapidly agitated with air, using a turbine stirring arrangement, until the pink color of the phenolphthalein just began to appear. The temperature was 16 to $18^{\circ} \mathrm{C}$. We assume that this pink color just appears at the point when all the excess of carbon dioxide is removed and the normal carbonate begins to be formed. Two volumes of $200 \mathrm{cc}$. each were now quickly measured off for analysis, in the one the lime was determined, in the other the carbon dioxide. The lime was found by evaporating the solution to dryness in a weighed platinum dish, and from the weight of calcium carbonate the weight of lime calculated. As pure marble lime had been used to make the original solution and as the residue was dried at $120^{\circ}$ in an air bath, we assumed that it was calcium carbonate. The carbon dioxide was determined gravimetrically by treating the measured volume of the solution in a flask with hydrochloric acid and driving out the gas by heat and a current of pure air and absorbing it in a weighed potash bulb. The following are the results obtained: 


\begin{tabular}{|c|c|c|}
\hline Weight of $\mathrm{CaO}$. & Weight of $\mathrm{CaO}_{2}$. & $\begin{array}{l}\text { Ratio of molecules } \\
\text { of } \mathrm{CO}_{2} \text { to one of CaO. }\end{array}$ \\
\hline $1 \ldots \ldots \ldots \ldots \ldots \ldots 0.0299$ & 0.0580 & 2.46 \\
\hline $2 \ldots \ldots \ldots \ldots \ldots \ldots 0.0552$ & 0.1360 & 3.13 \\
\hline $3 \ldots \ldots \ldots \ldots \ldots 0.0404$ & 0.0980 & 3.08 \\
\hline $4 \ldots \ldots \ldots \ldots \ldots \ldots 0.0657$ & $0.155^{8}$ & 3.02 \\
\hline $5 \ldots \ldots \ldots \ldots \ldots \ldots, 0.0555$ & O. 1288 & 2.95 \\
\hline $6 \ldots \ldots \ldots \ldots \ldots 0.0694$ & O. I 349 & 2.47 \\
\hline $7 \ldots \ldots \ldots \ldots \ldots 0.0864$ & 0.1943 & 2.86 \\
\hline $8 \ldots \ldots \ldots \ldots \ldots 0.0207$ & 0.0464 & 2.85 \\
\hline & & 2.84 \\
\hline
\end{tabular}

These results indicate that the composition of the acid calcium carbonate, when in dilute solution at the ordinary temperature, must be represented by the formula containing more than two molecules of carbon dioxide for one of lime. Our results indicate the formula $\mathrm{CaCO}_{3}$. I. $8\left(\mathrm{H}_{2} \mathrm{CO}_{3}\right)$ and this agrees fairly well with the determinations of Keiser and Leavitt who found the composition of the precipitated acid carbonate to correspond to the formula $\mathrm{CaCO}_{3} \cdot \mathrm{I} \cdot 75\left(\mathrm{H}_{2} \mathrm{CO}_{3}\right)$.

We also noticed that the solution of the acid carbonate of calcium which had been agitated with air until a faint pink color had appeared again became colorless on standing in the air, apparently, because this solution absorbed carbon dioxide from the air. The reverse is true of a solution of acid barium carbonate, this when it has been agitated with air until it is very faintly pink and is allowed to stand gradually becomes more deeply colored. Apparently the dissociation pressure of the carbon dioxide in the latter case is greater than in the former.

We have applied the same method of analysis to determine the composition of the acid carbonate of barium. The solution in this case was made by conducting carbon dioxide into a solution of barium hydroxide, containing a drop of phenolphthalein, until the pink color had disappeared and then continuing the current of gas until the barium carbonate had dissolved to a considerable extent. This solution of the acid barium carbonate was filtered and agitated with air until a very faint pink color appeared. Two portions were then measured off for analysis, and the carbon dioxide and the barium oxide determined by the method described above. The following results were obtained:

\begin{tabular}{|c|c|c|c|}
\hline No. & Weight of $\mathrm{BaO}$. & Weight of $\mathrm{CO}_{2}$. & $\begin{array}{l}\text { Ratio of molecules } \\
\text { of } \mathrm{CO}_{2} \text { to one of } \mathrm{BaO} \text {. }\end{array}$ \\
\hline I. . . & $\ldots 0.0648$ & $0.033^{8}$ & I. 82 \\
\hline $2 \ldots$ & $\ldots 0.0514$ & 0.0414 & $2,8 \mathrm{I}$ \\
\hline $3 \ldots$ & . o. 1786 & 0.1083 & 2. II \\
\hline $4 \cdots$ & . 0.0557 & 0.0407 & $2 \cdot 55$ \\
\hline $5 \cdots$ & $\ldots 0.0626$ & 0.0448 & 2.49 \\
\hline $6 .$. & $\ldots 0.1042$ & 0.0755 & 2.52 \\
\hline
\end{tabular}


These results indicate that the composition of the acid carbonate of barium in dilute solution at 15 to $16^{\circ} \mathrm{C}$. has a composition expressed by the formula $\mathrm{BaCO}_{3} \cdot \mathrm{I} \cdot 5\left(\mathrm{H}_{2} \mathrm{CO}_{3}\right)$. This confirms the results that we obtained from the analysis of the precipitated acid barium carbonate.

The experiments described in this paper were made in January and February, 1908, and it is our intention in the coming winter to apply the methods described to the determination of the composition of the acid carbonates of other metals.

WASHINGTON UNIVERSITY, ST. LoUis, Mo.

\section{THE PASSIVE STATE OF METALS.}

\section{A REVIEW OF THE LITERATURE AND THEORIES AND SOME EXPERIMENTS ON COBALT, IRON AND NICKEL.}

BY HORACE G. BYERS.

Received July I4, 1908 .

Contents.-(1) Introduction; (2) Periods of Investigation and References; (3) Theoretical; (4) Experimental-(a) Cobalt, (b) Iron, (c) Nickel; (5) Summary.

\section{Introduction.}

The literature upon the subject of passivity is already enormous and is rapidly accumulating in recent years. The theories and views are also rather numerous and conflicting. It seemed to me, therefore, it would be of assistance to chemists and perhaps stimulate work in this field if, in connection with my experimental work on cobalt, iron and nickel, I should give an outline of the literature and a brief review of the theoretical views. Several reviews have been published at various times, each with more or less complete references to the literature. These are as follows: Schönbein, "Das Verhalten des Eisens zum Sauerstoff," Basel (I837); Berzelius, Lehrbuch, Vol. II, p. 692 (1844); Wiedemann, Lehrbuch der Electricität, Vol. II, p. 8 I2 (I894); Ostwald, "Electrochemie, Ihre Geschichte und Lehre," p. 696 (1896); Sakur, Chem.-Ztg. , 28, 954 (1904); Fredenhagen, Z. physik. Chem., 63, I (1908). All of these are in German, and while it might seem desirable to publish such a review in English, ${ }^{1}$ the recent work of Fredenhagen would have deterred me were it not for the fact that he leaves out of sight the early literature and approaches the later work as an advocate for his own theory.

For the purpose of presentation it is perhaps convenient that the material presents itself in three rather well defined periods: (I) From the discovery of the phenomenon to the close of Schönbein's work, $1790-1838$. (2) From Schönbein to Hittorf, I $8.38-1898$. (3) The recent development, I $898-\cdots$.

${ }^{2}$ Heathcote, $J$. Soc. Chem. Ind., 26, 899 (1907), gives a list of references of the early literature but the journal is not to be had in Leipzig, and I am unaware as to how complete it is. 